\title{
A typological perspective on nominal concord
}

\author{
Mark Norris*
}

\begin{abstract}
This paper reports some of the results of the largest typological study of nominal concord to date. The sample contains 174 languages from 105 distinct families. Concord is found in $59.2 \%$ of languages in the sample. I demonstrate a number of tendencies among languages with concord: (i) number concord is the most common type, (ii) gender concord is common among languages with gender, (iii) case concord is relatively rare and almost never occurs alone, and (iv) it is more common to have concord on both adjectives and demonstratives than on just one or the other.
\end{abstract}

Keywords. morphology; typology; agreement; nominals; concord; features

1. Introduction. Nominal concord (hereafter just 'concord') is the process whereby modifiers (loosely speaking) in a nominal phrase inflect for morphosyntactic features of that nominal phrase. It commonly involves demonstratives and adjectives bearing this inflection, and the features involved are things like gender, number, and case. In many instances, the noun also reflects these features, and it is thus common to say things like "adjectives agree with the head noun" when describing or discussing concord. I present a few examples from different languages below. ${ }^{1}$

(1) French (fra) concord (gender-number):

the-F.SG plant(F).SG green-F.SG

'the green plant'

b. 1-e bâtiment vert

the-M.SG building(M).SG green.M.SG

'the green building'

(2) Estonian (ekk) concord (number-case):

a. kõigi-s nei-s raske-te-s küsimus-te-s

all.PL-INE these.PL-INE hard-PL-INE question-PL-INE

'in all these hard questions'

\footnotetext{
* For discussion of this and related work, I thank Martin Haspelmath, Raina Heaton, and Ruth Kramer. For assistance with data collection for this project, I thank Chase Carter, Lyosha Genzel, Lynden Hoge, Lindsay Jones, Robyn Kolozsvari, Jonathan Walls, Isaac Warren, and Ellie Wren-Hardin. Thanks as well to the audience at the 2019 meeting of the LSA. For financial support, I am grateful to the Office of the Vice President for Research at the University of Oklahoma. I am responsible for any errors herein. Author: Mark Norris, University of Oklahoma (mark-norris@ou.edu)

${ }^{1}$ Abbreviations in examples are as follows: ACC - accusative case, B - B gender, DAT - dative case, DEF - definite, DEM - demonstrative, DU - dual number, F - feminine gender, FUT - future tense, I - gender 1, III - gender 3, INE - inessive case, M - masculine gender, NOM - nominative case, OBL - oblique case, PL - plural number, SG - singular number, TRL - translative case. All language names are followed by their three-letter ISO 639-3 code in parentheses. Examples have their sources indicated. Unannotated examples are from the author's personal knowledge.
} 
b. selle-ks vahepealse-ks perioodi-ks

this-TRL in.betweeen-TRL period-TRL

'for this interim period'

(3) Wambaya (wmb) concord (gender-number-case):

a. ninagiyawulija janyi-nka hubaji-wuli-ja

that.I.DU.DAT dog.I-DAT small-DU-DAT

'those two small dogs (dative)'

(Nordlinger 1998:73)

b. bugayi alaji / buguwama jigama

big.I boy.I / big.III yam.III

'big boy' / 'big yam'

(Nordlinger 1998:47)

French has gender and number concord, expressed by the definite article and adjective in (1). Estonian has number and case concord, expressed by each of the words in the examples in (2). And Wambaya has concord for gender (I-IV), number, and case, expressed in various ways by the elements in the examples in (3).

It is my impression that concord is well-known in linguistics, perhaps due to its presence in well-documented European languages. Yet, it is not well-studied within the field, and the European pattern has received the most attention (in addition to Bantu languages), and these patterns are therefore viewed as typical of the phenomenon.

1.1. THE PRESENT STUDY. In this paper, I report some of the results of the largest typological investigation of concord to date, and the only study to focus specifically on concord (to my knowledge). ${ }^{2}$ The sample contains 174 languages from 174 distinct genera comprising 105 total families. It is a slightly pared-down version of WALS's 200-language sample, reduced in order to have a sample that is better-balanced as recommended by Dryer \& Haspelmath (2013).

The study investigates concord on three lexical categories: demonstratives, cardinal numerals greater than one (hereafter just "numerals"), and adjectives. ${ }^{3}$ We (working with a team of students) gathered examples where these elements modify an overt noun in a continuous nominal phrase. It is important that the element modify an overt noun, because in some languages, freestanding elements have different inflectional possibilities than those that modify an overt noun (see, e.g., Diessel (2013)). It is important that they form a continuous phrase, because in some languages, inflectional possibilities in continuous phrases are different from those in discontinuous phrases (Clem \& Dawson 2018). For data collection, we cast a wide net. For example, if a language had only a few examples distinguishing plural forms and those plural forms could be used attributively, we registered that as showing concord. It may be that a more careful analysis of some of these forms reveals the facts to be more complex than that. In fact, we're in a way inviting these sorts of critiques, both to strengthen our understanding of concord and to further clarify the description of these forms and languages that have them.

\footnotetext{
${ }^{2}$ Other studies have intersected with concord in various ways, and thus it does come up, but I emphasize again that it is not the focus of such studies. See especially Baker (2008), Nichols (1986, 1992), and Plank (1994). I discuss the study of gender concord by Bayırlı (2017) below.

${ }^{3}$ We looked only at numerals greater than one because the syntactic properties of one are known to be unique/special in some languages. I regrettably did not initially collect any information on one as a means to compare one vs. more than one, so I do not have any data on that question at this time. However, we have since started collecting data on one, but we have no results to share at this time.
} 
1.2. General ReSUlts (By REgion). Across the sample, we found evidence of concord in $59.2 \%$ of languages (103/174). Importantly, concord is found in all six major linguistic regions, as shown in Table 1. As we can see in Table 1, though concord is found in all six of these regions,

\begin{tabular}{rccccc}
\hline Region & Yes & $\%$ & No & $\%$ & Total \\
\hline Australia & 11 & $100 \%$ & 0 & $0 \%$ & 11 \\
Africa & 23 & $79.3 \%$ & 6 & $20.7 \%$ & 29 \\
N. America & 21 & $61.8 \%$ & 13 & $38.2 \%$ & 34 \\
Eurasia & 26 & $53.1 \%$ & 23 & $46.9 \%$ & 49 \\
S. America & 12 & $44.4 \%$ & 15 & $55.6 \%$ & 27 \\
Papunesia & 10 & $41.7 \%$ & 14 & $58.3 \%$ & 24 \\
\hline All & 103 & $59.2 \%$ & 71 & $40.8 \%$ & 174 \\
\hline
\end{tabular}

Table 1: Numbers of languages with concord by region

it is not uniformly distributed across them. In particular, it is more common in Africa and Australia. To be sure, there are languages of Australia without concord, it just happens that all of the languages in the sample do have concord based on the criteria considered here. In contrast, concord is noticeably rarer in Papunesia and perhaps South America. The percentages in North America and Eurasia are quite close to the worldwide percentage. ${ }^{4}$

From a genetic perspective, while there is only one language per genus in the sample, there are in some cases several genera from the same family. For families with 4 or more languages in the sample, percentages of languages showing concord or not are presented in Table 2. Based on

\begin{tabular}{rccccc}
\hline Family & Yes & $\%$ & No & $\%$ & Region \\
\hline Sino-Tibetan & 0 & $0 \%$ & 7 & $100 \%$ & Eur \\
Austronesian & 2 & $25 \%$ & 6 & $75 \%$ & Pap/Afr \\
Austro-Asiatic & 2 & $33.3 \%$ & 4 & $66.7 \%$ & Eur \\
Trans-New Guinea & 3 & $37.5 \%$ & 5 & $62.5 \%$ & Pap \\
Niger-Congo & 4 & $50 \%$ & 4 & $50 \%$ & Afr \\
Nakh-Daghestanian & 3 & $75 \%$ & 1 & $25 \%$ & Eur \\
Indo-European & 8 & $88.9 \%$ & 1 & $11.1 \%$ & Eur \\
Uto-Aztecan & 4 & $100 \%$ & 0 & $0 \%$ & NAm \\
\hline
\end{tabular}

Table 2: Concord in families with $\geq$ genera in the sample

these numbers, it does appear that there is some level of genetic stability, but there are also larger families (e.g., Trans-New Guinea or Niger-Congo) with roughly even numbers of languages with and without concord.

1.3. ASPECTS CONSIDERED IN THIS PAPER. Due to space constraints, I cannot discuss all aspects of the results of the study. Instead, I focus on discussing typological claims about concord that have been made in the literature. I consider first some aspects of the distribution of features in concord, e.g., gender, number, and case. Among other things, I find that languages with grammatical gender have a tendency to show concord, but the reverse (if concord, then gender) is not

${ }^{4}$ There is not uniform distribution in Eurasia. Concord is more common in Europe and Western Asia than in Eastern Asia. This may be ground for dividing Eurasia, but I have not yet explored this possibility carefully. 
well-supported. The second aspect I consider is the distribution of concord among word classes. I show that adjectives and demonstratives are both robustly attested participants in concord systems. I suggest there is not a strong difference in their propensity to participate, contrary to what I take to be a prevailing belief about concord, which is that adjectives are the hallmark example.

2. On grammatical gender and concord. There is an intuitive link between gender and concord, due (I surmise) to concord's common exemplification with Indo-European and Bantu languages. In a series of papers spanning almost two decades, Carstens $(2000,2001,2011,2018)$ has proposed that the properties of grammatical gender drive concord (among possibly other things). The relationship between gender and concord is also important for Bayırlı (2017). What is perhaps the most intriguing aspect of his investigation of concord involves gender concord, where he proposes two different universals connecting gender and concord. Because of these proposals, carefully scrutinizing the relationship of gender and concord is warranted. I take up that task in this section, considering primarily the generalizations discussed by Carstens and Bayirlı.

2.1. CONCORD IMPLIES NUMBER, BUT NOT GENDER. To begin, let us consider the distribution of features among the 103 languages with concord in the sample, shown in Table 3. Based strictly

\begin{tabular}{rcccc}
\hline Feature & Yes & $\%$ & No & $\%$ \\
\hline Gender & 58 & $56.3 \%$ & 45 & $43.7 \%$ \\
Number & 91 & $88.3 \%$ & 12 & $11.7 \%$ \\
Case & 30 & $29.1 \%$ & 73 & $70.9 \%$ \\
Definiteness & 9 & $8.7 \%$ & 94 & $91.3 \%$ \\
\hline
\end{tabular}

Table 3: Participation in concord systems by feature

on percentages, number concord is clearly the most common type across languages with concord, occurring in $88.3 \%$ of concord systems. Due to this, I propose the first Concord Tendency in (4). ${ }^{5}$

(4) Concord Tendency 1: If a language has concord, it likely has number concord.

The next most common feature in concord systems is gender, which appears in $56.3 \%$ of concord systems. On the basis of this number, I believe it is unreasonable to suggest that gender or gender concord are a prerequisite for concord. However, there still is a connection, which I discuss straightaway. Case concord and definiteness concord are noticeably rarer. I discuss case concord a bit more in section 2.3, and I set definiteness concord aside for the remainder of the paper. ${ }^{6}$

These proportions are based on all the languages in the sample, and there are languages in the sample without gender. As a result, the percentage of languages with gender concord is a bit understated. When we focus only on languages with a gender system, the affinity between gender

\footnotetext{
${ }^{5}$ I use the term tendency because these are not supported with statistical tests. As Dryer (1989) discusses, simple statistical tests are not appropriate for linguistic typological data, because the individual languages are not independent variables. Using a form of statistical analysis that is appropriate for non-independent variables is something I plan to do in future work, but I believe the patterns discussed here are interesting enough to warrant further investigation before that analysis can be completed.

${ }^{6}$ I must note that the category of definiteness concord or agreement is unclear. It is best known from Afro-Asiatic languages and Germanic languages. However, even in Germanic languages, the forms sometimes called definiteness agreement are not directly connected with definiteness as the name suggests (see, e.g., Pfaff's (2014) discussion of Icelandic or Roehrs's (2015) cross-Germanic investigation). For this study, if we found a grammar that described an alternation in form as connected to definiteness, we recorded it as such, but deep investigation of the usage of these forms in individual languages may reveal that definiteness is not the correct analysis.
} 
and concord emerges.

2.2. GENDER STRONGLY IMPLIES GENDER CONCORD. The total sample of 174 languages contains 69 languages with gender systems (based largely on the sample by Corbett 2013a). When we restrict our attention to those languages, the prevalence of gender concord increases to $79.7 \%$. The distribution according to numbers of genders is shown in Table 4 . This chart

\begin{tabular}{rccccc}
\hline \# Gender & Yes & $\%$ & No & $\%$ & Total \\
\hline 0 genders & $\mathbf{2}^{7}$ & $\mathbf{1 . 9 \%}$ & $\mathbf{1 0 1}$ & $\mathbf{9 8 . 1 \%}$ & $\mathbf{1 0 3}$ \\
\hline 2+ genders & $\mathbf{5 5}$ & $\mathbf{7 9 . 7 \%}$ & $\mathbf{1 4}$ & $\mathbf{2 0 . 3 \%}$ & $\mathbf{6 9}$ \\
2 genders & 24 & $75 \%$ & 8 & $25 \%$ & 32 \\
3 genders & 14 & $82.4 \%$ & 3 & $17.6 \%$ & 17 \\
4 genders & 6 & $75 \%$ & 2 & $25 \%$ & 8 \\
5+ genders & 11 & $91.7 \%$ & 1 & $8.3 \%$ & 12 \\
\hline Uncategorized & 0 & $0 \%$ & 2 & $100 \%$ & 2 \\
\hline
\end{tabular}

Table 4: Languages with and without gender concord

includes all 174 languages in the sample, not just the 103 languages with concord. It shows a fairly strong implication such that languages with grammatical gender likely exhibit gender concord (79.7\%). I thus propose a second Concord Tendency in (5).

(5) Concord Tendency 2: If a language has a grammatical gender system, it likely has gender concord.

Whatever it is that drives concord in language grammars, it clearly intersects with the place of grammatical gender.

However, this connection is likely one way, as other forms of concord still occur in $38.2 \%$ (44/115) of languages without grammatical gender in the sample. Adopting some form of Carstens's (2000, 2001, 2011, 2018) approaches, where gender facilitates or even drives concord, would only carry us part of the way. Norris's (2014) account, where concord is in part driven by feature percolation among nominal extended projections, is equally connected to gender and number, and thus it allows for languages with concord but no grammatical gender. Both kinds of approaches do not provide an explanation to the languages with gender but no gender concord. It is worth investigating the gender systems of such languages to see if they have anything in common.

Turning now to Bayırlı's (2017) investigation, he proposes two generalizations connecting gender to adjective concord. For reasons of space, I can discuss only the one presented below.

(6) Idiosyncratic Gender implies Concord: if a language has an idiosyncratic gender system, ${ }^{8}$ it has gender concord on adjectives (Bayırl1 2017:41).

\footnotetext{
7 The reader may be wondering how a language lacking nominal gender could nevertheless have gender concord. These are languages that were characterized by Corbett (2013a) as lacking nominal gender but with examples from grammars that are plausibly gender concord. The languages are Haida (hai), with an animacy-based system for demonstratives (but lots of what one might obliquely characterize as 'optionality'), and Chukchi (ckt), where we found some isolated examples of attributive demonstratives glossed as animate plural.

8 The term idiosyncratic gender is due to Bayırl, and it is opposed to systems with semantic gender. There are examples of languages that fit very clearly into each of those categories, but there are also borderline cases that are difficult to classify, and Bayırlı's criteria for dividing in this way were not clear to me.
} 
Bayırlı's sample is from WALS (Corbett 2013b), and thus there is significant overlap in our samples for this investigation. It is thus not surprising to find that this generalization is wellsupported by my sample. In fact, though Bayırlı (2017) focused almost exclusively on adjective concord, his generalization about idiosyncratic gender is without exception in my sample if we take cross-categorial view. Every language in the sample with what Corbett (2013b) calls a "semantic and formal" gender system has gender concord on some category or other. ${ }^{9}$ However, when we look at concord on individual lexical categories, there are a few exceptions to this kind of generalization.

In languages where demonstratives and adjectives both show concord, gender concord is generally marked on both. Focusing on demonstratives, there are 6 languages in the sample with gender concord and demonstrative concord in which gender is not part of demonstrative concord. 4 of those languages have a semantic gender system (Lak (lbe), Abkhaz (abk), Wardaman (wrr), and Nez Perce (nez)) and 2 have systems characterized as semantic and formal (Hindi (hin), Ingush (inh)). For example, in Ingush, there are 5-6 genders with largely arbitrary assignment, but demonstratives do not show gender concord.

(7) yz sag / yzh nax / yzh bier-azh

DEM.SG person / DEM.PL people / DEM.PL child-PL

'that person' / 'those people' / 'those children'

(Ingush, Nichols 2011)

Turning to adjectives, there are 5 languages in the sample with gender concord and adjective concord in which adjectives do not show gender concord. In 4 of those languages, the gender system is semantic (Burushaski (bsk), Ket (ket), Nez Perce (nez), and Chukchi (ckt)), and in the other (Jul'hoan (ktz)), it is semantic and formal. In Jul'hoan, there are 5 genders, and only demonstratives show gender concord. Adjectives show concord only for number, as shown in (8). ${ }^{10}$

$$
\begin{aligned}
& \text { jù jàn / jú jàn-sín } \\
& \text { person good / people(PL) good-PL } \\
& \text { 'a good person' / 'good people' }
\end{aligned}
$$

Thus, a version of Bayırlı's idiosyncratic gender universal in (6) where we consider gender concord on any category does not have any counterexamples in my sample. But Bayırlı's original formulation, which was only concerned with adjectives, is counterexemplified by Jul'hoan.

I turn now to another of Bayırlı's (2017) proposals, which defines implicational relationships between features in adjective concord.

2.3. CASE CONCORD RARELY OCCURS WITHOUT GENDER/NUMBER CONCORD. Bayirlı (2017:18) also proposes the Concord Hierarchy Generalization, which makes the predictions in (9).

\footnotetext{
${ }^{9}$ An important caveat: it is not always easy to determine whether a system is "purely semantic" vs. "semantic and formal." Corbett (2013b) collapses strictly semantic and predominantly semantic systems, which do have some arbitrariness (just not as much as languages with "semantic and formal" assignment).

${ }^{10}$ Bayırlı (2017:200) is aware of Jul'hoan but claims that adjectives are incorporated to nouns in the language and therefore do not show concord. Based on examples he presents and further examples I gathered, it is not clear that adjectives are incorporated, and in any case, Bayırlı does not elaborate on what incorporated adjectives would mean for Jul'hoan (formally speaking).
} 
(9) Bayırlı's Adjective Concord Hierarchy: case $\rightarrow$ number $\rightarrow$ gender; in other words...

a. Number concord implies gender concord (for adjectives)

b. Case concord implies number concord (for adjectives)

c. (transitively) Case concord implies gender concord (for adjectives)

This set of generalizations makes clear, testable predictions, and Bayırlı proposes formal analyses of languages that appear to run counter to this generalization. I do not discuss those analyses or their merits here, as my focus is on the typological patterns. While most languages in Bayırlı's sample conform to the predictions of the hierarchy, the sample is actually fairly unbalanced. Out of 30 languages in the sample, 15 are Indo-European, and 26 are Eurasian. Thus, it is worth asking whether this pattern is seen more broadly. In this section, I focus specifically on the case concord piece, showing that case concord rarely occurs without either gender or number concord in the world's languages.

Let us look first at case concord on its own merits. Case concord is rarer than gender and number concord, occurring in only $30 \%$ of languages with concord systems. If we look across all languages with case, we find that case concord occurs in only $25 \%(28 / 112)$ of such languages (+ 2 languages that Iggesen (2013) characterizes as lacking case). ${ }^{11}$

However, among those languages, Bayırlı's (2017) implication from gender/number to case holds up well (though not absolutely). In my sample, case concord rarely occurs in languages without gender or number concord (13.3\%; 4/30 languages with case concord). However, the only clear counterexample is Georgian (kat), which has what looks like ordinary inflectional plural-marking on nouns, but this is never repeated on attributive modifiers in continuous DPs. An example is provided in (10). ${ }^{12}$
(10) Nino
gogo-s $\operatorname{did}(*-\mathrm{eb})$
c'ign-eb-s iq'idi-s.
Nino.NOM girl-DAT big.DAT(*-PL) book-PL-DAT buy-FUT.3SG

'Nino will buy the girl big books.'

(Georgian, Fuchs 2018)

In (10), the adjective $d i d$ reflects dative case, but adding appropriate plural-marking results in an ungrammatical utterance. Thus, this is case concord without number concord, which runs counter to the hierarchy in (9). The other languages with case concord but no other type are Kutenai (kut), Kayardild (gyd), and Gooniyandi (gni). All three lack gender, and Kutenai and Kayardild arguably lack number as well. Gooniyandi may actually lack case concord, but I found one example in McGregor's (1990) grammar, so I counted it.

$$
\begin{aligned}
& \text { niya-ngga yoowooloo-ngga Roeburne Mick-ngga } \\
& \text { that-ERG man-ERG Roebourne Mick-ERG } \\
& \text { 'by that man Roebourne Mick' }
\end{aligned}
$$

I say it likely lacks case concord because McGregor (1990:277-278) states that the more common

\footnotetext{
${ }^{11}$ Iggesen (2013) characterizes Tagalog (tgl) and Kutenai (kut) as having no morphological case. In Tagalog, there are case particles/words as well as separate forms for demonstratives depending on case. In Kutenai, demonstratives show concord in obviation, which I have categorized as similar enough to case to count, insofar as it connects a noun phrase to its grammatical role.

${ }^{12}$ It is worth pointing out that Georgian is another language where inflection on elements in discontinuous nominal phrases may differ from inflection in continuous nominal phrases. Specifically, a discontinuous adjective bears plural-marking when the noun it is associated with does, unlike in a continuous nominal phrase. Fuchs (2018) argues that the optimal analysis of the pattern in Georgian is that both pieces are base-generated as separate constituents.
} 
pattern is for case to be expressed once per nominal phrase, although the precise position of that single expression of case is not fixed by the grammar.

So, when considering features of a concord system as a whole, we rarely find case occurring alone. On individual lexical categories, case concord still occurs rarely without some other type of concord, though there are more examples than just Georgian. In 4/17 (23.5\%) languages with numeral case concord, numerals lack either or both gender or number concord: Martuthunira (vma), Evenki (evn), Wardaman (wrr), and Nez Perce (nez). I provide an example from Evenki in (12).

$$
\begin{array}{ll}
\text { ilan-ma } & \text { oro-r-vo } \\
\text { three-ACC.DEF } & \text { reindeer-PL-ACC.DEF } \\
\text { 'three reindeer (accusative)' }
\end{array}
$$

Numerals in Evenki show concord for case (and when accusative, definiteness), but not for number. $^{13}$

In 5/29 (17.2\%) languages with demonstrative case concord, demonstratives lack either or both gender or number concord: Harar Oromo (hae), Tagalog (tgl), Wardaman (wrr), Ingush (inh), Nez Perce (nez). ${ }^{14}$ An example from Ingush is given in (13).

uq muo-cha boaqq-ii-cha naaxa

DEM.OBL like-OBL B.elder-PL-OBL people.ERG

'elders like them'

(Ingush, Johanna Nichols, p.c.)

While Ingush demonstratives do reflect case_-oblique in (13) and absolutive in (7) - they never reflect gender. This runs counter to the expectations of Bayırlı's hierarchy as applied to demonstratives, as neither case nor number concord are expected to occur without gender concord. However, strictly speaking, Bayırlı (2017) proposed the hierarchy only for adjectives.

Thus, when looking at concord systems in general, case concord rarely occurs alone. Among individual lexical items, there is still a strong tendency for case concord to occur with number concord and gender concord (in languages that have it), but there is a little bit more variation. I thus propose a third Concord Tendency in (14).

(14) Concord Tendency 3: If a language or lexical category within a language has case concord, it will likely have number concord (and if the language has gender, gender concord).

There is, of course, more to be said. I have not said anything in detail about possible implicational relationships between number and gender. Briefly, rather than a one-way implication as proposed by Bayırlı (2017), the relationship appears to be bidirectional. Among 35 languages

\footnotetext{
${ }^{13}$ It seems perhaps intuitive that a numeral would fail to reflect number in concord since number is clear from the meaning of the expression. That is, since a numeral like three will always appear in a noun phrase denoting a non-atomic set, it would not be possible to tell whether it reflects number. However, number is visible on numeral concord in some languages. It may be because numerals use morphemes that indicate plural rather than singular (as in, e.g., gender/number portmanteaux in Bantu languages). However, plural concord on numerals occurs even in languages without gender/number portmanteaux. For a special case where numerals can be either singular or plural, see Norris (2018a).

${ }^{14}$ In case there readers who are experts in Tagalog, I note that Tagalog would be best described as a language with a marginal concord system from a typological perspective, but based on our criteria, it had to be included. From a formal perspective, it might make more sense to characterize Tagalog as lacking concord. This is because it often shows up as a typologically rare language according to properties I have investigated.
} 
in the sample with number concord but no gender concord, only 6 have a gender system at all: Fur (fvr), Grebo (grj), Lakhota (lkt), Maranungku (zmr), Mixtec (Chalcatongo) (mig), and Tagalog ( $\operatorname{tgl}$ ). Those languages counterexemplify Bayırlı's hierarchy generalization, because it expects that languages with number concord will have gender concord if they have a gender system.

In addition, there are only 7 languages that have gender concord but no number concord: Apurinã (apu), Chinantec (Lealao) (cle), Maybrat (ayz), Slave (scs), Trumai (tpy), Wari' (pav), and Yurok (yur). These do not counterexemplify Bayırlı's generalization as stated. However, the fact that there are 52 languages that have both gender and number concord suggests that there is something special about those 7 languages with only gender concord, and a bidirectional implication between gender and number concord may be warranted. However, I stop short of proposing a Concord Tendency here.

Having discussed the presence of various features in concord systems, let us now turn to some aspects of concord across categories.

3. Concord by category: demonstratives versus adjectives. As mentioned at the outset, concord is often found on multiple syntactic categories within one nominal phrase. A pertinent issue is which category or categories are common in concord systems. On this matter, both Anderson (1992) and Corbett (2006) suggest that adjective concord is the most canonical form. ${ }^{15}$

(15) "The canonical example of this sort is agreement of adjectives with a noun they modify." (Anderson 1992:106)

(16) "In different domains targets which frequently show the behavior of canonical targets are adjectives and verbs."

(Corbett 2006:40)

However, these assertions were not based on typological data (so far as I was able to tell). It is impressionistically common to exemplify concord via adjective concord; perhaps this is the source for this intuition that adjectives are prototypical participants in concord.

In any case, we gathered data on concord by category in order to investigate this question. Identifying a canonical or typical category for concord would be useful for reasoning about the appearance of concord or devising theoretical models for it. If adjectives are indeed the most typical instance of concord, it would be reasonable to structure a model around properties of adjectives. After looking at the data from a variety of angles, it seems clear that adjectives are indeed typical in concord systems, but they are not alone. Demonstratives are roughly equally as common.

3.1. GENERAL DISTRIBUTION OF CONCORD BY CATEGORY. I present the breakdown of concord across categories in Table 5. There are 3 languages with concord that are not represented in Table 5; they all have concord only on determiners. Looking at the numbers in the tables, we can see that adjectives (A) and demonstratives (D) occur in large numbers of concord systems. There are numerically more languages with demonstrative concord, but the difference between demonstratives and adjectives is overstated in Table 5. This is because 7 languages with concord in the sample lack a clear adjective category and thus cannot show adjective concord. These lan-

\footnotetext{
15 To be fair, Corbett (2006) does not unequivocally state that adjectives are canonical, as he adds that articles, demonstratives, and various types of pronouns can show agreement. Examples of adjectives are highlighted in the section, but then examples of articles and demonstratives from French are given in prose. Thus, we might also take Corbett to suggest that adjectives, articles, and demonstratives are all equally canonical in concord.
} 


\begin{tabular}{rcc}
\hline Cat & $\#$ & $\%$ \\
\hline $\mathrm{D}$ & 22 & $21.4 \%$ \\
D-Num & 1 & $1.0 \%$ \\
D-A & 29 & $28.2 \%$ \\
D-Num-A & 35 & $34.0 \%$ \\
\hline Total & 87 & $84.5 \%$ \\
\hline
\end{tabular}

\begin{tabular}{rcc}
\hline Cat & $\#$ & $\%$ \\
\hline A & 11 & $10.7 \%$ \\
D-A & 29 & $28.2 \%$ \\
Num-A & 2 & $1.9 \%$ \\
D-Num-A & 35 & $34.0 \%$ \\
\hline Total & 77 & $74.8 \%$ \\
\hline
\end{tabular}

\begin{tabular}{rcc}
\hline Cat & $\#$ & $\%$ \\
\hline Num & 0 & $0.0 \%$ \\
D-Num & 1 & $1.0 \%$ \\
Num-A & 2 & $1.9 \%$ \\
D-Num-A & 35 & $34.0 \%$ \\
\hline Total & 38 & $36.9 \%$ \\
\hline
\end{tabular}

Table 5: Concord by category in 103 languages with concord

guages do not tell us anything about the frequency of adjective concord, and if we recalculate the frequency of adjective concord without those languages, it gets much closer to the frequency of demonstratives $(80.2 \%, 77 / 96)$.

In fact, concord on demonstratives and adjectives is so common that languages prefer to have concord on both demonstratives and adjectives $(64 / 103,62 \%)$ rather than just one or the other $(36 / 103,35 \%)$. The full figures are shown in Table 6, and a fourth Concord Tendency is given in (17).

\begin{tabular}{rcc}
\hline Cat & $\#$ & $\%$ \\
\hline D-Num-A & 35 & $34.0 \%$ \\
D-A & 29 & $28.2 \%$ \\
\hline Total & 64 & $62.1 \%$ \\
\hline
\end{tabular}

\begin{tabular}{rcc}
\hline Cat & $\#$ & $\%$ \\
\hline D & 22 & $21.4 \%$ \\
A & 11 & $10.7 \%$ \\
D-Num & 1 & $1.0 \%$ \\
Num-A & 2 & $1.9 \%$ \\
\hline Total & 36 & $35.0 \%$ \\
\hline
\end{tabular}

Table 6: Concord with both demonstratives and adjectives (left) and not both (right)

(17) Concord Tendency 4: If a language has concord, it is more likely that it will have concord on both adjectives and demonstratives than on just one or the other.

The only 3 languages in the sample with concord that have neither demonstrative nor adjective concord are languages that I have categorized as having only concord on determiners or something determiner-like (Khoekhoe (naq), Ndyuka (djk), Alamblak (nmp)). The examples below exemplify morphemes in Alamblak that Bruce (1984) dubs "terminators."

Alamblak "terminators"

a. ind bro fëh-r

DEM big pig-3SG.MASC

'the big pig'

(Alamblak, Bruce 1984:90)

b. ind fëh bro-r

DEM pig big-3SG.MASC

'the BIG pig'

(Alamblak, Bruce 1984:90)

It seems plausible to me that these terminators could be a kind of determiner. Bruce (1984) asserts that terminators are descriptively different from both demonstratives and adjectives.

Thus, when looking at concord overall, demonstratives and adjectives show concord roughly equally as often. To consider the relationship from another angle, let us focus on just number concord. 
3.2. NUMBER CONCORD ON DEMONSTRATIVES AND ADJECTIVES. Number concord is the most common participant in concord systems. Thus, if number concord is typical in concord systems, then we could consider expression of number concord as being indicative of typical behavior in concord. ${ }^{16}$ For example, if demonstratives show concord for number more regularly than adjectives (or vice versa), we could take this as evidence that they are more basic in concord systems. The distribution of number concord on demonstratives and adjectives is shown in Table 7 below. This Table includes only languages that have number concord at all. In most lan-

\begin{tabular}{rcc}
\hline Concord on Dem? & $\#$ & $\%$ \\
\hline No & 13 & $14.3 \%$ \\
Yes, +Number & 75 & $82.4 \%$ \\
Yes, -Number & 3 & $3.3 \%$ \\
\hline Total (Dem) & 91 & \\
\hline
\end{tabular}

\begin{tabular}{rcc}
\hline Concord on Adj? & $\#$ & \\
\hline No & 17 & $19.5 \%$ \\
Yes, +Number & 68 & $78.2 \%$ \\
Yes, -Number & 2 & $2.3 \%$ \\
\hline Total (Adj) & 87 &
\end{tabular}

Table 7: Presence of number concord on demonstratives (left) and adjectives (right)

guages with demonstrative concord and number concord, demonstratives participate in the number concord system. Only 3 languages have demonstrative concord and number concord but no number-marking on demonstratives: Harar Oromo (hae), Iraqw (irk), and Tagalog (tgl). For adjectives, on the right, the number is similarly small. Only 2 languages with adjective concord and number concord do not have number concord on adjectives: Barasano (bsn) and Paumarí (pad). Thus, evidence from number concord also suggests that adjectives and demonstratives are equally central to concord systems.

3.3. FULL VS. REDUCED CONCORD IN DEMONSTRATIVES AND ADJECTIVES. Finally, let us turn to languages that have concord systems involving more than one feature. In such languages, we can define two types of exponence patterns, which I dub FULL CONCORD and REDUCED CONCORD. Some formal definitions for these terms are provided below.

- Full Concord: A category $\mathscr{C}$ in a language $\mathscr{L}$ shows Full Concord if for every feature $\mathscr{F}$ in the concord system of $\mathscr{L}, \mathscr{C}$ expresses $\mathscr{F}$.

- Reduced Concord: A category $\mathscr{C}$ in a language $\mathscr{L}$ shows Reduced Concord if $\mathscr{C}$ expresses concord AND for some feature $\mathscr{F}$ in the concord system of $\mathscr{L}, \mathscr{C}$ does not express $\mathscr{F}$.

To further explicate these terms, I use two examples from Wambaya (wmb), presented in (19) below.

(19) Full and reduced concord in Wambaya (wmb)

a. ninagiyawulija janyi-nka hubaji-wuli-ja

that.I.DU.DAT dog.I-DAT small-DU-DAT

'those two small dogs (dative)'

b. gujarrawulu marndag-bulu inuwuliyaga

(Nordlinger 1998:73)

two.ACC white.person-DU.ACC that.I.DU.ACC

'those two white people (accusative)'

(Nordlinger 1998:133)

${ }^{16}$ Also, see section 2.2 for discussion of adjectives and demonstratives lacking gender concord, which also occurs with very similar frequency. 
Concord in Wambaya involves gender (I, II, III, IV), number, and case. Demonstratives express all three of these features, e.g., ninagiyawulija expresses gender, number, and case. Thus, demonstratives show full concord. However, the adjective hubajiwulija 'small' in (19a) does not express gender, and the numeral gujarrawulu 'two' in (19b) does not express gender (or number). Accordingly, we can say that these elements express reduced concord in Wambaya.

I raise the distinction between full and reduced concord as an additional way to compare the concord behavior of demonstratives and adjectives. If, for example, demonstratives show full concord more frequently than adjectives, we could take this to indicate that demonstrative concord is more typical than adjective concord. The types of concord shown by adjectives and demonstratives are given in Table 8. This table includes all instances where demonstratives or ad-

\begin{tabular}{rcc}
\hline Concord type & $\#$ & $\%$ \\
\hline Full & 42 & $48.3 \%$ \\
Reduced & 30 & $34.5 \%$ \\
Indeterminate & 15 & $17.2 \%$ \\
\hline Total (Dem) & 87 & \\
\hline
\end{tabular}

\begin{tabular}{rcc}
\hline Concord type & $\#$ & $\%$ \\
\hline Full & 41 & $53.2 \%$ \\
Reduced & 27 & $35.1 \%$ \\
Indeterminate & 9 & $11.7 \%$ \\
\hline Total (Adj) & 77 & \\
\hline
\end{tabular}

Table 8: Full and reduced concord in demonstratives (left) and adjectives (right)

jectives show concord in a language, not just examples where they express multiple features. The row labeled "Indeterminate" includes situations where the concord system of the language only involves one feature. In these languages, there can be no reduced concord, as the full set contains only one feature, and failure to express that one feature is then failure to show concord. There are also languages where only one category shows concord. In effect, there can be no reduced concord in these languages either, as the sole category showing concord also defines the set of features active in the concord system. These are grouped with "Full" in the chart above. Importantly, the percentage of languages with reduced concord on demonstratives is nearly identical to the percentage of languages with reduced concord on adjectives. Therefore, frequency of reduced concord is another domain in which there is very little difference between demonstratives and adjectives.

4. Conclusion. In this paper, I discussed some of the results of a typological study of concord (and its absence) in 174 languages. We saw that languages with gender have an affinity for concord, but the implication is only one way (gender $\rightarrow$ concord) and not absolute. I believe this means that whatever drives concord (formally or functionally) is connected to the place of grammatical gender, but they must be at least partially independent. The results certainly raise questions about development and loss of gender and concord. We could investigate languages that lost grammatical gender to see when/if they lost concord as well (e.g., in the history of English) with the aim of seeing whether concord aids in the preservation of gender systems (or vice versa).

We also saw that case concord almost always occurs with gender and/or number concord. Though this is strongest when looking at the system as a whole, there is also a tendency for individual lexical categories to show gender and/or number concord in addition to case concord. This supports a view of case concord whereby it is somehow dependent on the mechanism for gender/number concord. Most existing treatments of case concord (e.g., Babby (1987), Matushansky (2008), Pesetsky (2013)) do not generally explore gender/number concord in detail. However, the account I proposed in Norris 2018b, based on work in my dissertation (Norris 2014), does provide a foothold for understanding case concord's dependence on other forms of concord, which I 
note here.

I proposed universal feature percolation principles in Norris 2014 which distribute features of gender and number throughout the nominal extended projection. Concord qua operation can be viewed as the postsyntactic insertion of AGR nodes and application of Feature Copying, which ensure that those distributed gender and number features are realized morphologically by the various heads showing concord. The distribution of case features throughout the nominal extended projection is not regulated by the same feature percolation principles as gender and number, but a separate operation. The end result is that case, gender, and number are all represented on the same nodes, and this is where the dependence of case concord on gender/number concord would be encoded. What is needed for case concord is an operation to spread case features and an operation of AGR node insertion and Feature Copying to get those features exponed. The operation of Feature Copying would copy features from nodes that have case features, but also gender and number features due to the feature percolation principles. On the other hand, there are plenty of languages with gender/number concord but no case concord. In Norris's (2014) system, these languages would lack the operation that spreads case feature values. Thus, for Norris (2014), case concord is dependent on gender/number concord because both use the Feature Copying operation, and feature percolation of gender/number is universal, so any instance of copying case features to AGR nodes would pick up gender/number automatically. I leave a more careful explication of this interaction to future work. ${ }^{17}$

Finally, I looked at the prevalence of adjective and demonstrative concord from three different viewpoints: overall frequency of concord, tendency to show number concord, and tendency to show full/reduced concord in concord systems involving multiple features. In all three cases, there was minimal difference between adjectives and demonstratives. Accordingly, I proposed that adjectives and demonstratives are equally integral to concord systems. Formal analyses of concord should then extend equally well to demonstratives and adjectives. This is not an issue for any existing account of concord that I am aware of, but it could come up given that demonstratives and adjectives have syntactic differences.

Turning to future work, I note two immediate types of tasks. First, I plan to continue collecting data. In particular, it seems clear that gathering more data from (i) languages with case concord and (ii) languages with grammatical gender would sharpen interesting theoretical points connected to those kinds of languages. However, the sample we have now is already large enough to start considering theoretical consequences, both within theories of concord and their intersection with other corners of the grammar. That is the second task I aim to explore more seriously in the immediate future. I note two domains here. First, as already mentioned, case concord seems to piggyback on existing systems of number (and gender) concord. It is worth considering how we might derive this fact from the formal mechanisms at play. Second, the order of morphemes on elements showing concord is in many cases the same as the order of morphemes on the noun, e.g., adjective-NUM-CASE noun-NUM-CASE. ${ }^{18}$ This raises questions for the structure of featural representations and for the mechanism(s) of agreement manipulating those representations.

\footnotetext{
${ }^{17}$ One important part of this exploration would be to characterize what is different about Georgian from any other Georgian-like language, i.e., any other language with case concord but no number concord despite what seems like a robust number system.

18 There are, of course, issues of syncretism and Fusion/cumulative exponence that obscure this for some languages. Importantly, for number and case, I am not aware of any instances where the order of elements showing concord is the reverse of the order on the noun.
} 


\section{References.}

Anderson, Stephen. 1992. A-morphous Morphology. Cambridge: Cambridge University Press.

Babby, Leonard. 1987. Case, prequantifiers, and discontinuous agreement in Russian. Natural Language \& Linguistic Theory 5(1). 91-138. https://doi.org/10.1007/bf00161869.

Baker, Mark. 2008. The Syntax of Agreement and Concord. Cambridge: Cambridge University Press.

Bayırl, İsa Kerem. 2017. The universality of concord: Massachusetts Institute of Technology dissertation.

Bruce, Les. 1984. The Alamblak language of Papua New Guinea (East Sepik), vol. 81 Pacific Linguistics: Series C. Canberra: Research School of Pacific and Asian Studies, Australian National University.

Carstens, Vicki. 2000. Concord in minimalist theory. Linguistic Inquiry 31(2). 319-355. https: //doi.org/10.1162/002438900554370.

Carstens, Vicki. 2001. Multiple agreement and case deletion: Against $\varphi$-incompleteness. Syntax 4(3). 147-163. https://doi.org/10.1111/1467-9612.00042.

Carstens, Vicki. 2011. Hyperactivity and hyperagreement in Bantu. Lingua 121(5). 721-741. https://doi.org/10.1016/j.lingua.2010.11.001.

Carstens, Vicki. 2018. Concord and labeling. ms, Southern Illinois University-Carbondale. https://ling.auf.net/lingbuzz/003637.

Clem, Emily \& Virginia Dawson. 2018. The emergence of case matching in discontinuous DPs. ms, University of California-Berkeley.

Corbett, Greville. 2006. Agreement. Cambridge: Cambridge University Press.

Corbett, Greville G. 2013a. Number of genders. In Matthew S. Dryer \& Martin Haspelmath (eds.), The world atlas of language structures online, Leipzig: Max Planck Institute for Evolutionary Anthropology. http://wals.info/chapter/30.

Corbett, Greville G. 2013b. Systems of gender assignment. In Matthew S. Dryer \& Martin Haspelmath (eds.), The world atlas of language structures online, Leipzig: Max Planck Institute for Evolutionary Anthropology. http://wals.info/chapter/32.

Dickens, Patrick J. 2005. A concise grammar of Jul'hoan with a Jul'hoan-English glossary and a subject index. Köln: Rüdiger Köppe.

Diessel, Holger. 2013. Pronominal and adnominal demonstratives. In Matthew S. Dryer \& Martin Haspelmath (eds.), The world atlas of language structures online, Leipzig: Max Planck Institute for Evolutionary Anthropology. https://wals.info/chapter/42.

Dryer, Matthew S. 1989. Large linguistic areas and language sampling. Studies in Language 13. 257-292.

Dryer, Matthew S. \& Martin Haspelmath (eds.). 2013. WALS online. Leipzig: Max Planck Institute for Evolutionary Anthropology. http://wals.info/.

Fuchs, Zuzanna. 2018. Separating case connectivity and movement: Evidence from Georgian split DPs. ms, Harvard University.

Iggesen, Oliver A. 2013. Number of cases. In Matthew S. Dryer \& Martin Haspelmath (eds.), The world atlas of language structures online, Leipzig: Max Planck Institute for Evolutionary Anthropology. http://wals.info/chapter/49.

Matushansky, Ora. 2008. A case study of predication. In F. Marušič \& R. Žaucer (eds.), Studies in formal slavic linguistics: Contributions from formal description of slavic languages 6.5, 213-239. Frankfurt am Main: Peter Lang. 
McGregor, William. 1990. A functional grammar of Gooniyandi Studies in Language: Companion Series. Amsterdam/Philadelphia: John Benjamins.

Nedjalkov, Igor. 1997. Evenki. London: Routledge.

Nichols, Johanna. 1986. Head-marking and dependent-marking grammar. Language 56-119. https://doi.org/10.2307/415601.

Nichols, Johanna. 1992. Linguistic diversity in space and time. University of Chicago Press.

Nichols, Johanna. 2011. Ingush grammar. University of California Press.

Nordlinger, Rachel. 1998. A grammar of Wambaya, Northern Territory (Australia). Canberra, Australia: Research School of Pacific and Asian Studies, Australian National University.

Norris, Mark. 2014. A theory of nominal concord: University of California, Santa Cruz dissertation.

Norris, Mark. 2018a. The morphosyntax of number in Estonian numeral-noun constructions. In Patrick Farrell (ed.), Proceedings of the linguistic society of america, vol. 3, 45:1-13.

Norris, Mark. 2018b. Unmarked case in Estonian nominals. Natural Language \& Linguistic Theory 36. 523-562. https://doi.org/10.1007/s11049-017-9377-9.

Pesetsky, David. 2013. Russian Case Morphology and the Syntactic Categories. Cambridge, MA: MIT Press.

Pfaff, Alexander. 2014. Inside and outside- before and after: weak and strong adjectives in Icelandic. In Frank Van de Velde, Petra Sleeman \& Harry Perridon (eds.), Adjectives in Germanic and Romance: variation and change Linguistik Aktuell, 217-244. Amsterdam: John Benjamins Publishing Company.

Plank, Frans. 1994. What agrees with what in what, generally speaking? In Frans Plank (ed.), Agreement gender number genitive (EUROTYP working papers VII/23), 39-58. Berlin: European Science Foundation.

Roehrs, Dorian. 2015. Inflections on pre-nominal adjectives in germanic: Main types, subtypes, and subset relations. The Journal of Comparative Germanic Linguistics 18(3). 213-271. https: //doi.org/10.1007/s10828-015-9076-z. 